\title{
Raoul De Houdenc, La vengeance Raguidel
}

\section{G. Matteo Roccati}

\section{(2) OpenEdition}

\section{Journals}

\section{Édition électronique}

URL : http://journals.openedition.org/studifrancesi/35666

DOI : 10.4000/studifrancesi.35666

ISSN : 2427-5856

\section{Éditeur}

Rosenberg \& Sellier

\section{Édition imprimée}

Date de publication : 1 juillet 2005

Pagination : 128

ISSN : 0039-2944

\section{Référence électronique}

G. Matteo Roccati, «Raoul De Houdenc, La vengeance Raguidel », Studi Francesi [En ligne], 145 (XLIX |

I) | 2005, mis en ligne le 30 novembre 2015, consulté le 20 avril 2021. URL : http://

journals.openedition.org/studifrancesi/35666 ; DOI : https://doi.org/10.4000/studifrancesi.35666

\section{Ce document a été généré automatiquement le 20 avril 2021.}

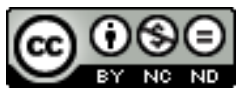

Studi Francesi è distribuita con Licenza Creative Commons Attribuzione - Non commerciale - Non opere derivate 4.0 Internazionale. 


\title{
Raoul De Houdenc, La vengeance Raguidel
}

\author{
G. Matteo Roccati
}

\section{RÉFÉRENCE}

RAOUL DE HOUDENC, La vengeance Raguidel, édition critique par GILLES ROUSSINEAU, Genève, Librairie Droz («Textes littéraires français», 561), 2004, pp. 494.

1 L'édition est précédée d'une longue introduction (pp. 7-141) qui présente d'une manière claire et documentée l'intérêt de l'oeuvre et les problèmes qu'elle soulève. Tout d'abord sont traitées les questions concernant la date (première décennie du XIII ${ }^{\mathrm{e}}$ siècle) et l'auteur; le débat critique qui a surgi à son sujet depuis la première édition du texte, en 1862, est retracé de manière précise. L'examen des parentés entre la Vengeance et l'autre roman sûrement de Raoul, Meraugis de Portlesguez - parentés lexicales et dans la pratique de la versification, ainsi que parentés stylistiques, moins probantes -, fait pencher vers l'hypothèse d'un même auteur pour les deux oeuvres. Le dossier de l'identification de Raoul avec le neveu, modeste chevalier, de Pierre le chantre, est ensuite repris et cela permet de mieux cerner la personnalité du poète, même s'il ne s'agit que d'une hypothèse vraisemblable.

2 Un chapitre est ensuite consacré à «L'esprit de l'oeuvre: tradition et création littéraires», dans lequel G. R. relève les parentés littéraires avec l'oeuvre de Chrétien et d'autres récits arthuriens. Il traite de l'image, à la fois positive et ironique, de Gauvain, héros principal du roman et qui en assure l'unité, de l'humour et de la parodie des thèmes arthuriens, de la place réduite du merveilleux, utilisé «seulement à des fins dramatiques», enfin du «sens de l'observation juste et du détail réaliste» (p. 60).

3 Cette présentation s'achève ainsi: «Raoul de Houdenc était un grand artiste. La versification de son poème comme son art de la description témoignent parfois d'une belle virtuosité, toujours d'un vrai talent. Son roman manque peut-être d'unité, mais il ne lasse pas. On lit avec un réel plaisir chaque histoire, qui est allégrement contée sur 
un rythme vif et soutenu. Surtout, on est séduit par l'humour permanent de l'auteur, par sa manière toute personnelle de prendre une distance ironique et souriante à l'égard des personnages qu'il met en scène et dont il montre les illusions et les déconvenues, les espoirs et les épreuves. Emule de Chrétien de Troyes, il a cherché à se détacher des stéréotypes arthuriens légués par la tradition romanesque pour créer une oeuvre subtile, attachante et originale» (p. 63).

4 Vient ensuite l'étude de la tradition manuscrite. On y trouvera la description des deux manuscrits et des deux fragments qui transmettent le texte, ainsi que l'examen de ce que nous connaissons d'un autre manuscrit, aujourd'hui perdu et disparu sans doute dès le XVII ${ }^{e}$ siècle. Suit la justification du choix du manuscrit de base (M: Nottingham, University Library, Mi LM 6) et de la présentation du texte. L'introduction s'achève par l'étude de la langue du copiste et de l'auteur, l'analyse du roman, la bibliographie et les illustrations (quatre miniatures du manuscrit de Nottingham).

5 Dans l'édition (6108 vers) les leçons rejetées sont indiquées en bas de page, les variantes suivent (pp. 331-349), ainsi que, en annexe aux variantes («Pierre Borel, lecteur d'un manuscrit disparu»), le «relevé complet des mentions et citations» du roman par P. B. dans son «Trésor de recherches et antiquités gauloises et françaises», Paris, 1635. Les notes (pp. 351-406), la table des noms propres (pp. 407-411) et le glossaire (pp. 413-491) terminent le volume. 